\title{
Medulloepithelioma of the central nervous system
}

INSERM

\section{Source}

INSERM. (1999). Orphanet: an online rare disease and orphan drug data base.

Medulloepithelioma of the central nervous system. ORPHA:251883

Medulloepithelioma of the central nervous system is a rare, primitive neuroectodermal tumor characterized by papillary, tubular and trabecular arrangements of neoplastic neuroepithelium, mimicking the embryonic neural tube, most commonly found in the periventricular region within the cerebral hemispheres, but has also been reported in brainstem and cerebellum. It usually presents in childhood with headache, nausea, vomiting, facial nerve paresis, and/or cerebellar ataxia, and typically has a progressive course, highly malignant behavior and poor prognosis. Hearing and visual loss have also been observed. 